\title{
Proceeding
}

10th INSHS International Christmas Sport Scientific Conference, 4-5 December 2015. International Network of Sport and Health

Science. Szombathely, Hungary

\section{Physical activity of Czech schoolchildren in the autumn season}

\author{
TOMÁŠ VESPALEC ${ }^{1}$, JINDŘICH PAVLÍK ${ }^{1}$, MARTIN ZVONAŘ ${ }^{1}$, TOMÁŠ ZEMAN² \\ 1 Department of Kinesiology, Masaryk University, Brno, Czech Republic \\ 2 Department of Biochemistry, Masaryk University, Brno, Czech Republic
}

\begin{abstract}
The aim of the study was to measure and subsequently evaluate the quantitative and qualitative factors of physical activity (PA) of primary school pupils in the Czech Republic in the autumn period using an objective method and to assess whether these factors differ significantly before and after clock shift from the summer time (Daylight Savings Time) to winter time. The data were acquired from 37 pupils (20 boys, 17 girls) aged 10-13, at primary schools in Brno (CZE) in the period from 22 October to 26 October 2014 and subsequently from 12 November to 16 November 2014. PA was measured using the Actigraph GT3X accelerometer (Actigraph corp., USA) in the week when the clocks were changed, on 26 October 2014 and two weeks later. Three business days and two weekend days were measured. The monitored characteristics included those related to energy output, movement time according to intensity and the number of steps. Changes in measured characteristics after the clock shift were tested statistically using Wilcoxon signed-rank test. Throughout the business days the pupils demonstrated more than med $>10000$ steps a day and MVPA did not fall under med $>60 \mathrm{~min} /$ day. However, during the weekend these values did not exceed 6600 steps a day 39 min MVPA/day. When comparing the results of all the investigated PA factors before and after the clock shift, significant differences have been found only in boys during business days for moderate PA ( $p=$ $0.02)$ and MVPA $(p=0.04)$. The study has revealed substantial differences between PA of children during business days when compared to days off in the autumn period. However, the changes in the PA structure before and after the winter clock shift have only been diagnosed at the level of moderate PA and MVPA in boys, even though the daytime duration has been reduced significantly by more than one hour from 10 hours 23 minutes before to 9 hours and 16 minutes after the clock shift. Key words: ACCELEROMETRY, ACTIGRAPH, CHILDREN
\end{abstract}

\footnotetext{
Corresponding author. Department of Kinesiology, Faculty of Sports Studies, Masaryk University, Kamenice 5, 62500 Brno, Czech Republic

E-mail: vespalec@fsps.muni.cz

10th INSHS International Christmas Sport Scientific Conference, 4-5 December 2015. International Network of Sport and Health Science. Szombathely, Hungary.

JOURNAL OF HUMAN SPORT \& EXERCISE ISSN 1988-5202

(C) Faculty of Education. University of Alicante

doi:10.14198/jhse.2016.11.Proc1.04
} 


\section{INTRODUCTION}

Physical activity defined as "any bodily movement associated with muscular contraction that increases energy expenditure above resting levels”(EU Working Group „Sport \& Health", 2008), has become an issue discussed intensively at the global level.

The development of modern civilization and consumerism lead to reduced amount and intensity of physical activity across the whole population group from children to senior citizens. This phenomenon is usually labelled by experts as sedentary lifestyle (Etemadi et al., 2012; Tremblay et al., 2010; Tudor-Locke, Craig et al., 2013). At the end of the last century and at the beginning of this century a number of studies reported the tendency towards a significant PA reduction in children attending school, often connected with increasing rates of overweight and obesity (Herman et al., 2015). Therefore the need has arisen to measure, diagnose and describe - by objective methods - the real PA level in different groups of the population.

The research focused on PA monitoring generally utilizes certain basic methods, from observation and questionnaires to instrumental measurements. Questionnaire surveys are relatively popular as they enable easy data acquisition from a large number of respondents. However, overvaluation in subjective answer evaluation might present a certain disadvantage (Gray et al., 2015).For this reason, some instrument-based PA measurement methods can be deemed optimal. Due to simplicity and sufficient validity of results (Crouter et al., 2013; Rothney et al., 2008), we have selected triaxial accelerometers as the most suitable for our study.

Another, no less significant aspect playing a crucial role in PA monitoring, is the weather at the time of measurement (Edwards et al., 2015).Another aspect of identical gravity, which is usually neglected by the majority of studies, might be the season and hence the length of the day (daylight). When these issues are applied to the region of Central Europe, namely the Czech Republic where the research took place, the weather records for 2014 show that the longest day (21June) lasted 16 hours and 20 minutes and the shortest day (22December) lasted 8 hours and 7 minutes (average data of all available measuring stations in the Czech Republic), (ČHMÚ, 2014). The data prove that the difference between the longest and the shortest day is more than double, which can have a significant effect on the individual's PA quantity and intensity throughout the day. However, the change in day length in the course of the year is gradual. The times of clock shifts between the summer and winter time are rather specific as the time of sunrise and sunset changes immediately. Therefore the study focuses on the period of the autumn clock shift, when the difference in day length measured at the beginning and the end of a two-week period was more than one hour.

If the potential influence of daylight on the human psyche is disregarded as well as the somewhat speculative effect on the individual's biorhythm (Kikuchi, 1986), one can determine the real PA amount and intensity performed by the individual as an objective factor of human activity in relation to day length.

The aim of the study thus was to measure and subsequently evaluate the quantitative and qualitative PA factors of primary school pupils in the Czech Republic in the autumn period using an objective method and to assess whether these factors differ significantly before and after the clock shift from the summer time (Daylight Savings Time) to winter time.

\section{MATERIAL AND METHODS}


The study is based on data obtained from the pupils of two primary schools in the region of Brno (CZE) in the period of autumn 2014 in the course of two measuring sessions. The measuring sessions took place from 22 October to 26 October 2014 and subsequently from 12 November to 16 November 2014. The research sample was acquired on the basis of availability. No randomization techniques were applied during the data collection.

The data collection was carried out on the basis of an approval granted by the Ethics Committee of the Faculty of Sports Studies, Masaryk University and of the informed consent of the participants' legal representatives. All data handling was performed in compliance with the Declaration of Helsinki ethical standards (Harriss \& Atkinson, 2013).

\section{Participants}

59 pupils from ZŠ Sirotkova primary school (26) and ZŠ Laštůvkova primary school (33) aged 10-13 took part in the measuring session. The data from 37 respondents (20 boys and 17 girls) were used in the research. A more detailed characteristic of the research set is given in table1. The data of other participants needed to be excluded from the research as incomplete.

Table 1. Research sample age profile

\begin{tabular}{lccc}
\hline & Research sample $[\mathrm{n}]$ & & \\
\hline Age & GIRLS & BOYS & TOTAL \\
\hline 10 years & 2 & 5 & 7 \\
11 years & 9 & 10 & 19 \\
12 years & 6 & 3 & 9 \\
13 years & & 2 & 2 \\
10 -13 years & 17 & 20 & 37 \\
\hline
\end{tabular}

\section{Measures}

PA was measured using the triaxial Actigraph GT3X accelerometer (Actigraph corp., USA). Three business days were measured continually, followed by two weekend days. The measurement took place every day from 7 a.m. to 9 p.m. five days a week (from Wednesday to Sunday). As mentioned above first measurement was realised in the period from 22 October to 26 October 2014 and subsequently second from 12 November to 16 November 2014. The term of clock shift was 26 October 2014 at 2 a.m.

The respondents were wearing the measuring device throughout the day on an elastic band around their waist, in the frontal area of the hips, but took it off for the night. The respondents also took the device off to have showers and baths. Considering the measurement method and in order to ensure safety the respondents had been instructed not to use the device when engaging in water sports or if its placement on the body would present a safety risk to the participant.

For business days the data from 37 pupils were processed, as mentioned above. However, from the weekend measurements, only the data from 25 pupils were suitable for use (12 boys, 13 girls).

The individual values were obtained by averaging the values measured during the observed periods (three business days before clock shift, two weekend days before clock shift, three business days after clock shift, two weekend days after clock shift). 


\section{Data Analyses}

RAW data were transferred from the device to the Actilife programme (Actigraph corp., USA) and converted. From the programme outputs, in particular the characteristics related to energy output, PA time and its detailed classification according to intensity and the number of steps were further used. PA intensity is classified in the standard way (Rothney et al., 2008; Strong et al., 2005) as light (1.5-3 METs), moderate (36 METs), and vigorous (>6 METs). MVPA is subsequently the sum of moderate and vigorous PA - often referred to as "Moderate to Vigorous PA" (Mcclain et al., 2007).

Changes in measured characteristics before and after the clock shift were tested statistically using Wilcoxon signed-rank test. Software R (R Core Team, Austria) was used for all statistical computations. A difference was considered statistically significant when respective $p$ value was less than significance level of 0.05 .

\section{RESULTS}

\section{Business Days}

During the business days the MET rate was above the level of $1.8 \mathrm{MET}$ for boys and girls, as shown by both the first and the second measurement. During measurements before and after the clock shift, both groups exceeded 60 minutes / day of physical activity with intensity moderate to vigorous (MVPA), which is the amount recommended by the EU Working Group „Sport \& Health" (2008) and WHO (2010). The median value of the number of steps exceeded 11000 steps a day in both groups according to the first measurement and did not fall under 10000 steps a day according to the second measurement. More detailed data are provided in table 2 and in figure 1.

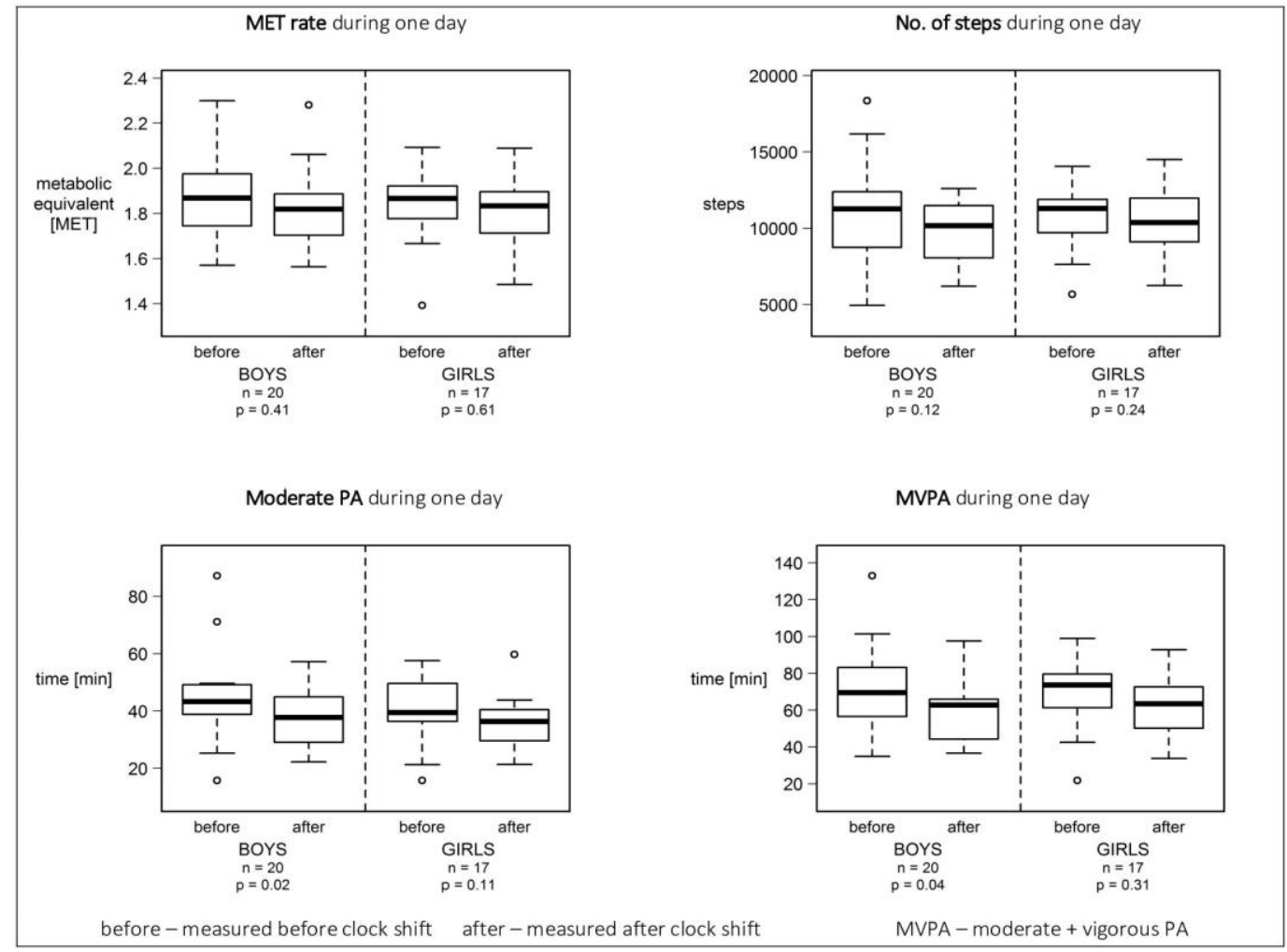

Figure 1. PA during business days - basic characteristics and comparison of their values before and after clock shift using Wilcoxon signed-rank test. 


\section{Weekend Days}

The time that girls spent engaged in PA of moderate to vigorous intensity (MVPA) was shorter by more than a half when compared to the values measured during business days and according to the second measurement, if even fell under 30 minutes / day. The difference in MVPA between business days and the weekend was not so significant for boys and the median of the first as well as the second weekend measurement did not fall under 37 minutes / day. Relatively low values in relation to the recommendation (Duncan et al., 2007) were also found for the number of steps during the day as the median value did not exceed 6600 steps a day for either one of the groups. See table 2 and figure 2.

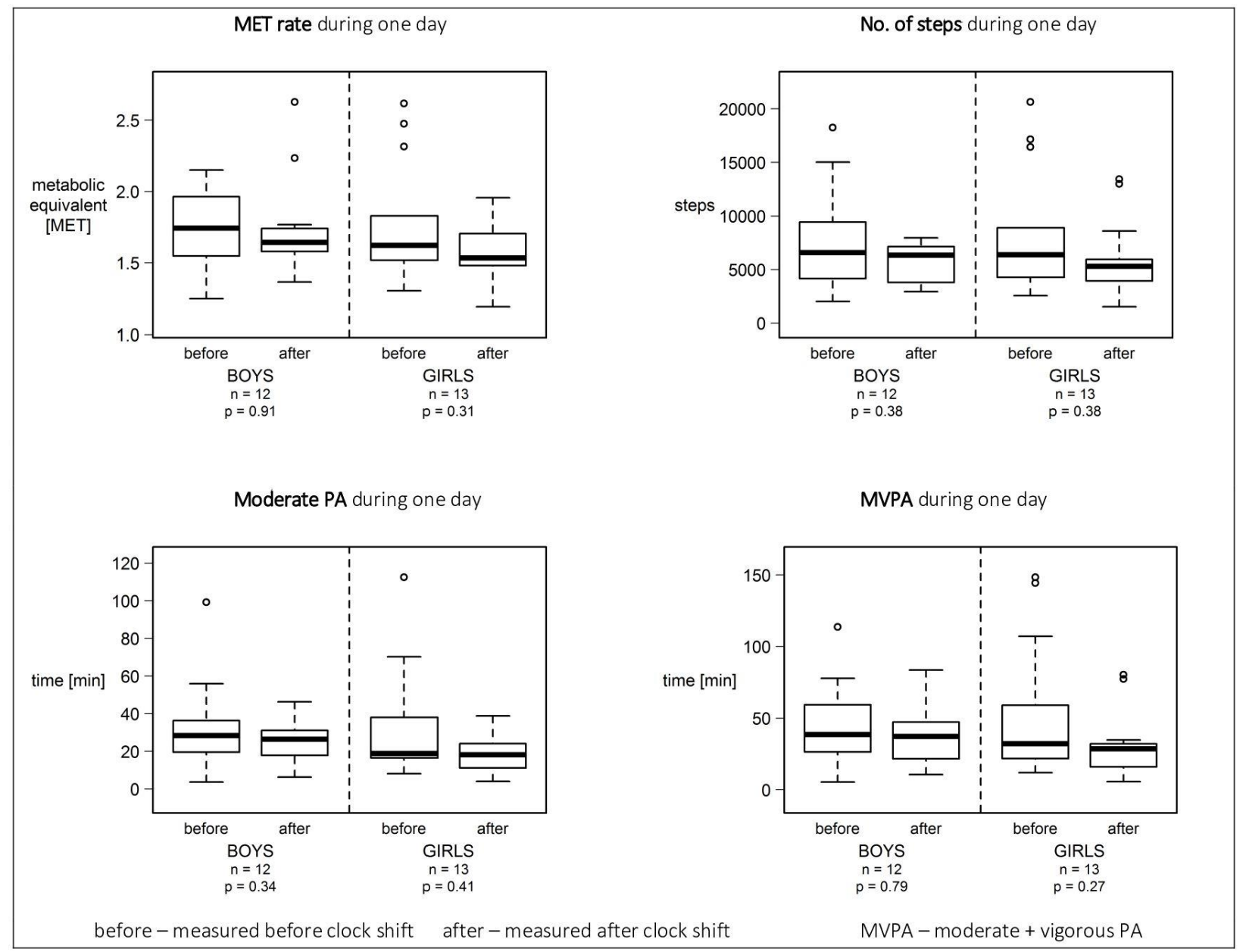

Figure 2. PA during weekend - basic characteristics and comparison of their values before and after clock shift using Wilcoxon signed-rank test.

\section{Measurement Comparison Before and After Clock Shift}

Generally, it can be stated that the values recorded before the clock shift were higher for all variables than those recorded by the second measurement. However, a more detailed data analysis using the Wilcoxon signed-rank test did not prove statistical significance of this difference, as illustrated in table 2 . The difference 
in the moderate PA factor $(p=0.015)$ and in the MVPA factor $(p=0.044)$ for boys during business days were the only two instances considered significant.

Table 2. PA - Basic characteristic and results of Wilcoxon signed-rank test before and after clock shift using Wilcoxon signed-rank test.

\begin{tabular}{|c|c|c|c|c|c|c|c|c|c|c|c|}
\hline & & & BUSINE & DAYS & & & & WEEY & & & \\
\hline & Variable & $\begin{array}{l}\text { median } \\
\text { before }\end{array}$ & $\begin{array}{c}\text { median } \\
\text { after }\end{array}$ & W+ & W- & $p$ & $\begin{array}{c}\text { median } \\
\text { before }\end{array}$ & $\begin{array}{c}\text { median } \\
\text { after }\end{array}$ & $\mathrm{W}+$ & W- & $p$ \\
\hline GIRLS & MET rate & 1,87 & 1,83 & 88 & 65 & 0,611 & 1,62 & 1,53 & 61 & 30 & 0,305 \\
\hline & light PA [min/day] & 204,61 & 193,94 & 91 & 62 & 0,517 & 193,58 & 173,17 & 66 & 25 & 0,168 \\
\hline & moderate PA [min/day] & 39,5 & 36,39 & 111 & 42 & 0,109 & 18,92 & 18,17 & 58 & 33 & 0,414 \\
\hline & vigorous PA [min/day] & 26,92 & 24,94 & 83 & 70 & 0,782 & 13,83 & 8,83 & 62 & 29 & 0,273 \\
\hline & MVPA [min/day] & 73,75 & 63,56 & 99 & 54 & 0,306 & 32,17 & 28,58 & 62 & 29 & 0,273 \\
\hline & steps [n/day] & 11307 & 10376,67 & 102 & 51 & 0,243 & 6385 & 5306 & 59 & 32 & 0,376 \\
\hline BOYS & MET rate & 1,87 & 1,82 & 128 & 82 & 0,409 & 1,74 & 1,64 & 37 & 41 & 0,91 \\
\hline & light PA [min/day] & 223,75 & 211,03 & 132,5 & 77,5 & 0,313 & 167,17 & 156,67 & 41 & 37 & 0,91 \\
\hline & moderate PA [min/day] & 43,33 & 37,83 & 169 & 41 & 0,015 & 28,46 & 26,5 & 52 & 26 & 0,339 \\
\hline & vigorous PA [min/day] & 23,75 & 19,06 & 134 & 76 & 0,294 & 10,71 & 10,75 & 29 & 49 & 0,47 \\
\hline & MVPA [min/day] & 69,56 & 62,86 & 159 & 51 & 0,044 & 38,58 & 37,25 & 43 & 35 & 0,791 \\
\hline & steps [n/day] & 11273,92 & 10173,33 & 147 & 63 & 0,123 & 6591,75 & 6338 & 51 & 27 & 0,38 \\
\hline
\end{tabular}

Legend: $\mathrm{V}+=$ sum of positive ranks. V- = sum of negative ranks. Median before = median value before clock shift. Median after $=$ median value after clock shift

\section{DISCUSSION}

The recorded data demonstrate that although there was a decrease in the values between the first and the second measurement, generally this difference is not significant. This fact implies that in particular during business days, when children attend school, they follow a relatively regular schedule that is not strongly affected by the length of the day.

However, during data processing we came across other connections that were not the primary goal of the study. The comparison of data from a business day and the weekend showed two trends:

1. Majority of children experience significant PA decrease in the autumn period during the weekend when compared to the business days;

2. Despite the general PA decrease, the tested set includes individuals whose PA is higher at the weekend and highly exceeds the recommendation of 60 minutes per day.

The PA decrease at weekends might be related to the perception of this time as the time to relax in some families, which affects the attitude to planning how to spend this time. In general, it is not to be expected that inactive people will provide their children with intensive PA activities at weekends. Therefore this is the potential area for further education focused on PA, in particular towards families. The data show that at the time when children attend school their PA is adequate in many cases. As far as the time distribution of PA 
throughout the day is concern, the data of most children show that a substantial part of their PA during the whole day is performed at the time of school hours or at the time of travelling to and from school.

The second trend demonstrates a striking difference among some pupils. We believe it is related mostly to performing sports activities during the weekend. The data analysis showed repeatedly higher weekend MVPA values for certain individuals. Thus it can be assumed these are children who regularly participate in sports competitions at weekends or their PA for the weekend is systematically organized by their parents.

Considering the season of the year when the research was carried out, before the start of the research we were worried about possible effect of adverse weather conditions on measurement execution. For this reason it should be noted that the weather at the time of both measuring sessions was relatively favourable. As illustrated in table 3 , the average temperatures (day and night) were oscillating between $5^{\circ} \mathrm{C}$ and $12^{\circ} \mathrm{C}$ and the maximum day temperatures reached $18^{\circ} \mathrm{C}$. No continuous rain or poor air quality occurred at the research location. Therefore the impact of the weather on the research can be considered minimal.

Table 3. Weather conditions during measurement.

\begin{tabular}{lccccc}
\hline \multicolumn{7}{c}{ Weather during measurements } \\
DATE & 22.10. & 23.10. & 24.10. & 25.10. & 26.10. \\
avg. temp $\left[{ }^{\circ} \mathrm{C}\right]$ & 9,1 & 8,4 & 7,9 & 5,1 & 6,6 \\
\hline & 12.11. & 13.11. & 14.11. & 15.11. & 16.11. \\
DATE & 11,6 & 9,9 & 7,9 & 10,9 & 8,5 \\
avg. temp $\left[{ }^{\circ} \mathrm{C}\right]$ & \multicolumn{7}{c}{} \\
\hline
\end{tabular}

On the other hand, the change in the time of sunrise and sunset was significant. At the first measuring session the average sunrise time was 7:26 a.m. and sunset time 5:26 p.m. At the second measuring session after clock shift the average sunrise time was 6:59 a.m. and sunset time 4:15 p.m. Thus while the daylight time on the first day was approximately 10 hours 23 minutes, on the second day daylight lasted on average only 9 hours 16 minutes. Moreover, the sunset occurred markedly earlier and when one considers a model example when the pupil gets home from school at 3 p.m., he or she only has 75 minutes of daylight left after getting home. The time when children can perform outdoor activities requiring light is thus very short in this season.

The results focus on the description of the recorded data as well as a comparison with the recommendations of the EU working group and WHO. We are aware that other sources, e.g. (American College of Sports Medicine, 2013; Martinez-Gomez et al., 2010) may state different values recommended by the authors. However, we believe that in particular the adequate level of MVPA, at the minimum level of 60 min/day constitutes one of the key factors for healthy motor development of children and for this reason it is stressed within the data processing.

It should also be noted the study demonstrates certain limits. The very form of data collection using the triaxial accelerometers means complications with recording activities not based on locomotion (cycling, inline skating...) or activities taking place e.g. in water (Herman Hansen et al., 2014). Certain distortion of the results can also be caused by the motivation of research participants to achieve the best possible values and increase activity temporarily for the time of the measurements. We tried to eliminate this factor by processing the results anonymously as the monitored individuals were not presented any feedback on the values. 
During business days, when children attended school, the measurements were not affected by any specific activities (trip, special teaching forms, ...) and the teaching schedule at the time of school attendance was almost identical during both measuring sessions. However, the weekend activities of the children were completely within the competence of the families and were not influenced by the research team in any way. This fact might thus have affected the weekend PA values depending on the weekend activities the children participated in. That might have created a situation when the weekend data show greater differences among certain individuals within the group.

Given the research set selection method, the conclusions of the study are not generally applicable to the society as a whole.

\section{CONCLUSIONS}

The study has produced some interesting findings about the quantitative and qualitative PA factors in children attending school in the autumn season.

During business days when children attend classes, the physical activity of the majority of them can be marked as sufficient, as for quantity (number of steps) as well as PA intensity (MVPA). However, many children demonstrated an alarming decrease in PA during the weekend, when many of them did not exceed 30 min MVPA per day and the number of steps taken did not reach 5000 steps a day. From the point of view of gender, it can be stated that there are no significant differences between boys and girls in the majority of the result areas.

In relation to the immediate change in day length at the time of the autumn clock shift from summer to winter time it was found that although the measured PA characteristics showed a decrease in the values after the clock shift, the change is not considered significant. A significant change was diagnosed only in the group of boys during business days in the area of moderate PA and MVPA.

Generally it can be stated that no significant impact of the autumn clock shift on the quality of PA was found in primary school pupils. However, a marked difference was diagnosed between PA during business days and at weekends.

Further research should verify whether the established trend of significant PA decrease during weekends in children attending school is typical solely for the autumn season or whether a similar change is demonstrated throughout the year.

\section{REFERENCES}

1. American College of Sports Medicine. (2013). ACSM's Guidelines for Exercise Testing and Prescription. Lippincott Williams \& Wilkins.

2. Crouter, S. E., Horton, M., \& Bassett, D. R. (2013). Validity of ActiGraph Child-Specific Equations during Various Physical Activities: Medicine \& Science in Sports \& Exercise, 45(7), 1403-1409. http://doi.org/10.1249/MSS.0b013e318285f03b

3. ČHMÚ. $(2014,5)$. Informační stránky Českého hydrometeorologického ústavu. Retrieved from http://www.infomet.cz/index.php?id=read\&idd=1403347889

4. Duncan, J. S., Schofield, G., \& Duncan, E. K. (2007). Step count recommendations for children based on body fat. Preventive Medicine, 44(1), 42-44. http://doi.org/10.1016/j.ypmed.2006.08.009 
5. Edwards, N. M., Myer, G. D., Kalkwarf, H. J., Woo, J. G., Khoury, P. R., Hewett, T. E., \& Daniels, S. R. (2015). Outdoor Temperature, Precipitation, and Wind Speed Affect Physical Activity Levels in Children: A Longitudinal Cohort Study. Journal of Physical Activity \& Health, 12(8), 1074-1081.

6. Etemadi, A., Golozar, A., Kamangar, F., Freedman, N. D., Shakeri, R., Matthews, C., ... Dawsey, S. M. (2012). Large body size and sedentary lifestyle during childhood and early adulthood and esophageal squamous cell carcinoma in a high-risk population. Annals Of Oncology: Official Journal Of The European Society For Medical Oncology / ESMO, 23(6), 1593-1600. http://doi.org/10.1093/annonc/mdr494

7. EU Working Group „Sport \& Health". (2008, řijen). EU Physical Activity Guidelines. Retrieved from http://ec.europa.eu/sport/library/policy_documents/eu-physical-activity-guidelines-2008_en.pdf

8. Gray, C., Gibbons, R., Larouche, R., Sandseter, E. B. H., Bienenstock, A., Brussoni, M., ... Tremblay, M. S. (2015). What Is the Relationship between Outdoor Time and Physical Activity, Sedentary Behaviour, and Physical Fitness in Children? A Systematic Review. International Journal Of Environmental Research And Public Health, 12(6), 6455-6474. http://doi.org/10.3390/ijerph120606455

9. Harriss, D. J., \& Atkinson, G. (2013). Ethical Standards in Sport and Exercise Science Research: 2014 Update. International Journal of Sports Medicine, 34(12), 1025-1028.

10. Herman Hansen, B., Børtnes, I., Hildebrand, M., Holme, I., Kolle, E., \& Anderssen, S. A. (2014). Validity of the ActiGraph GT1M during walking and cycling. Journal of Sports Sciences, 32(6), 510 516.

11. Herman, K. M., Chaput, J.-P., Sabiston, C. M., Mathieu, M.-E., Tremblay, A., \& Paradis, G. (2015). Combined Physical Activity/Sedentary Behavior Associations With Indices of Adiposity in 8- to 10Year-Old Children. Journal of Physical Activity \& Health, 12(1), 20-29.

12. Kikuchi, Y. (1986). The Importance of Human Ergology. Journal of Human Ergology, 15(1), 1-2. http://doi.org/10.11183/jhe1972.15.1

13. Martinez-Gomez, D., Ruiz, J. R., Ortega, F. B., Veiga, O. L., Moliner-Urdiales, D., Mauro, B., ... Sjöström, M. (2010). Recommended Levels of Physical Activity to Avoid an Excess of Body Fat in European Adolescents: The HELENA Study. American Journal of Preventive Medicine, 39(3), 203211. http://doi.org/10.1016/j.amepre.2010.05.003

14. Mcclain, J. J., Sisson, S. B., \& Tudor-Locke, C. (2007). Actigraph Accelerometer Interinstrument Reliability during Free-Living in Adults: Medicine \& Science in Sports \& Exercise, 39(9), 1509-1514. http://doi.org/10.1249/mss.0b013e3180dc9954

15. Rothney, M. P., Schaefer, E. V., Neumann, M. M., Choi, L., \& Chen, K. Y. (2008). Validity of Physical Activity Intensity Predictions by ActiGraph, Actical, and RT3 Accelerometers. Obesity, 16(8), 194652. http://doi.org/http://dx.doi.org/10.1038/oby.2008.279

16. Strong, W. B., Malina, R. M., Blimkie, C. J. R., Daniels, S. R., Dishman, R. K., Gutin, B., ... Trudeau, F. (2005). Evidence Based Physical Activity for School-age Youth. The Journal of Pediatrics, 146(6), 732-737. http://doi.org/10.1016/j.jpeds.2005.01.055

17. Tremblay, M. S., Colley, R. C., Saunders, T. J., Healy, G. N., \& Owen, N. (2010). Physiological and health implications of a sedentary lifestyle. Applied Physiology, Nutrition \& Metabolism, 35(6), 725740.

18. Tudor-Locke, C., Craig, C. L., Thyfault, J. P., \& Spence, J. C. (2013). A step-defined sedentary lifestyle index: <5000 steps/day. Applied Physiology, Nutrition \& Metabolism, 38(2), 100-114.

19. WHO. (2010). Global recommendations on physical activity for health. Retrieved from http://apps.who.int/iris/handle/10665/44399. 